\title{
Environmental audit as a tool for socio- economic evaluation \& security management of an industrial enterprise
}

\author{
Sergey Yashin ${ }^{1,}$, Sergey Borisov ${ }^{1}$, and Dmitry Sukhanov ${ }^{2}$ \\ ${ }^{1}$ Nizhny Novgorod State University n.a. N.I.Lobachevsky, 603950 Gagarin avenue, Nizhny \\ Novgorod, Russia \\ ${ }^{2}$ Autonomous non-profit organization of additional professional education «BIOTA», 603006, \\ Varvarskaya street 7, Nizhny Novgorod
}

\begin{abstract}
In this paper, the authors consider environmental audit as a tool for managing the safety of an industrial enterprise. The objects of the study are the industrial enterprises of the Nizhny Novgorod region. The subjects of the study are: the concept, the legal framework, the stages of evolution, the structure and methods of environmental audit. In particular, the authors consider a specific example of the use of internal environmental audit methods to assess the socio-economic efficiency of the innovative project to reduce industrial injuries in industrial enterprises. As tools and methods of analysis, the authors propose to use the author's approach to the calculation and assessment of the cost of damage from occupational injuries, based on the Danish method of assessing the effectiveness of innovative projects with a pronounced environmental component in the field of prevention of occupational injuries, taking into account the damage arising from the "loss of well-being". One of the significant proposals of the authors to conduct this study are reasoned proposals to finalize the existing and accepted in the Russian Federation methodology for assessing the economic losses of the organization from industrial injuries and occupational diseases.
\end{abstract}

\section{Introduction}

Initially, the term "audit" (literally translated as "I hear") was born in the financial sphere and is still actively used in this very meaning. In the field of finance, auditing refers to an independent financial inspection by experts in checking of financial reporting, payment statements, tax returns, etc. [1].

In addition to the financial sphere, the concept of "audit" was also widely adopted in other areas, such concepts appeared as: operational audit, technical audit, environmental audit, quality audit, and some others. Certain types of audit are very close in their content to certification.

\footnotetext{
* Correspondingauthor: jashinsn@yandex.ru
} 
Environmental audit is a relatively new concept in Russian practice. However, some enterprises that apply the principles of environmental auditing have already felt the benefits of using it.

The subject of consideration in this paper is the environmental audit as a tool for managing the safety of an industrial enterprise. Within the study, the authors studied the evolution of the environmental audit process, its regulatory and legal framework, the specifics of the formation and development of this area in the Russian Federation, the structure of environmental auditing at an industrial enterprise.

In the practical part of the work, the author's approach to the assessment of innovative projects aimed at reducing industrial injuries at industrial enterprises is proposed. It has been substantiated that the existing project assessment methodologies do not sufficiently take into account the specifics of projects related to ecology and life safety. The author's improvements to the existing methodology, based, inter alia, on the Danish model, which takes into account the loss of well-being due to injury, are given. The authors also estimated the socio-economic efficiency of an innovative project aimed at reducing industrial injuries in the enterprise on the basis of their proposed methodology.

\section{Materials and methods}

In order to proceed to the application of environmental auditing methods to improve the effectiveness of enterprise safety management, it is necessary to consider the concept, essence, regulatory framework, evolution and structure of environmental auditing, the direction and features of the application of environmental auditing in an industrial enterprise.

According to the ISO 14000 quality standard, an environmental audit is understood as a systematic documented verification process, consisting in obtaining objectively and evaluating the evidences of auditing [2].

It is aimed at establishing the compliance of environmentally significant activities, events, conditions of management systems or information on these issues with auditing criteria. The results of the environmental audit are communicated to the client.

From the point of view of environmental management, environmental auditing acts as a link in a complex multi-level system of relations between economic entities with each other and with higher authorities. It is a tool that includes organizational and economic factors of environmental protection. Thus, it is the most important element of the economic mechanism of environmental regulation. Using the tools of environmental auditing, it is possible to determine the best option for environmental protection measures, to make an economic assessment of technical and technological improvements, to organize information and analytical control over the state and degree of operation of ecological-safety equipment.

Environmental audit is a comprehensive, documented verification process of objectively identifying and evaluating information to determine whether the criteria for checking specific environmental measures, activities, conditions of management systems or information about them are met, and informing the consumer about the results obtained during this process [3].

The environmental audit originated at the turn of the 1970s-1980s, in particular, in the EEC, the directive on environmental auditing was adopted in 1982.

In Russia, the environmental audit has been used since 1993. In 1998, a number of legal acts of the State Committee on Ecology were adopted as part of an environmental audit, including those that established the rules for their certification [4].

Environmental audit, as an instrument of environmental law and the environment, sufficiently developed in the world, is still quite new for Russia. Currently, only a few 
investment companies and banks take into account the probability of investment risk from the point of view of environmental security when deciding on a loan [5].

In 2001, the Russian Federation adopted the Federal Law "On Auditing" [6]. In this regulatory act, auditing activity is defined as entrepreneurial activity for independent verification of accounting and accounting (financial) statements of organizations and individual entrepreneurs. The content of the environmental audit is not limited only to the verification of accounting and financial reporting on the interaction of society and nature, it is much broader.

To determine the place of environmental audit in the system of environmental law, it is necessary to determine in relation to which environmentally significant activity it is carried out.

Environmental auditing is carried out in the process of privatization of state and municipal enterprises, in the implementation of bankruptcy procedures, in the conduct of compulsory environmental insurance, in the preparation of investment projects and programs, when this is provided for by the terms of investment.

An enterprise (institution, organization) that carries out industrial, economic, defense and other activities, and actively interacts with the external environment, is considered as object of environmental audit.

An enterprise, in carrying out its main activity, which includes products issuing, implementation of works or services, must ensure rational use of natural resources, environmental protection, as well as its own protection from the negative effects of environmental pollution. The scale and type of impact of the enterprise on the environment, and, on the contrary, its resistance to the impact of a polluted natural object substantially depend on the main type of activity of the enterprise, on the degree of its danger to the environment and on the environment.

Accordingly, in the process of environmental audit, it is necessary to certify compliance with the legislation, instructions and rules for the environmental activities of an enterprise, taking into account the specifics of its main type of activity.

The certification function of eco-auditors in the Russian Federation is currently performed by several organizations. Among them are such as: the non-profit partnership "National Ecological Audit Chamber" and the non-profit partnership "Ecological international Community. Certification" (NP "EMMASSert").

The main goals and objectives of environmental auditing are the following:

Justification of environmental policies and strategies;

$\checkmark \quad$ Analysis and assessment of the environmental aspects of economic and other projects;

$\checkmark$ Analysis and assessment of regulatory acts in the field of environmental protection;

$\checkmark \quad$ Justification and initiation of environmental activities;

$\checkmark \quad$ Identification of environmental problems of production and territories;

Environmental audit is divided into obligatory and initiative. In this framework, the following types can be found:

$\checkmark$ Assessment of the effectiveness of the environmental management system;

$\checkmark$ Estimation of economic damage from pollution;

$\checkmark$ Waste hazard assessment;

$\checkmark$ Estimation of energy consumption and suggestion of the ways to reduce it;

$\checkmark$ Environmental risk assessment in case of accidents and man-made disasters; them.

Detection of the environmental problems and the development of solutions to solve

Thus, based on the above, it can be concluded that environmental auditing is an important element in assessing the safety of companies and a tool for developing measures to eliminate environmental problems. 
In addition to the general objectives of environmental audit listed above, we will dwell in more detail on the objectives of conducting this type of audit in an enterprise [7].

Consider the list of such goals in more detail.

$\checkmark \quad$ One of the important points for conducting an environmental audit is a thorough check of the enterprise's activities regarding compliance with the rules and procedures for environmental protection;

$\checkmark \quad$ Drafting a series of recommendations on environmental safety activities;

$\checkmark$ Development of an efficient and optimized management scheme for facilities that are responsible for environmental protection;

Independent assessment ofcosts for natural resources use.

As we know, many enterprises on the territory of the Russian Federation, and not only there, strive to reduce the costs of environmental activities in their companies as much as possible. At the same time, their main strategies are "closing their eyes" to the problems of the environmental safety of their company, which, as a result, often leads to "extra" costs associated either with fines of regulatory authorities, or with compensation for material and moral damage to the victims, which occurred due to non-compliance of labor protection requirements.

In order to avoid such costs and properly assess their costs of ensuring labor protection, we need tools for environmental management and environmental auditing.

Environmental auditing gives undoubted advantages to companies that have implemented it in their practice.

These benefits include as follows:

$\checkmark \quad$ The owners of the company will be able to collect reliable and complete information from several sources about the compliance of their company with environmental standards;

$\checkmark \quad$ Helps develop an enterprise strategy, tactics and policy;

$\checkmark$ Reduce the risk in case of an emergency at the enterprise;

$\checkmark$ Allows finding a solution on the issue of taxation in the case of the introduction of resource-saving technologies;

$\checkmark$ Allows creating a detailed plan for the negative impact on the environment of the activity;

$\checkmark \quad$ To increase the attractiveness of manufactured goods and services in the external and internal markets, as well as investment attractiveness;

$\checkmark$ Simplify obtaining a loan for the future activities of the enterprise;

$\checkmark$ Obtain quality certificates according to international environmental standards;

Find a common solution in the field of environmental insurance.

Thus, the environmental audit allows the company to get a clear, clear picture on the issue of security management at the enterprise, to make it more attractive in the eyes of the investor by complying with international environmental standards, to avoid certain environmental accidents and man-made disasters, to protect the company's personnel from various damage.

The efficiently established environmental management and audit system of the company, as well as the understanding of the company's management and employees of the importance of carrying out activities in the field of occupational safety and health allows company not only to be "clean" in the eyes of the labor safety authorities, but also really saves the health of the company's employees.

In addition, contrary to the popular belief, the expenses of conducting an environmental audit and the formation of an environmental management system may be significantly lower than the possible damage caused by the payment of a large amount of fines to regulatory authorities. It is also important to consider that in addition to the payment of fines in the event of an insured event, you will have to pay a large amount to the victims. No wonder they say if you buy cheaply, you pay dearly. Therefore, it is better to build an 
effective system by investing once a large amount of money than to pay serious fines and compensate the injured workers [8]. Specific measures for labor protection in the enterprise should be developed when the environmental management system is established and adjusted and continuously improved during the environmental audit.

Environmental audit is an initiative, with the exception of cases stipulated by the legislation of the Russian Federation.

Due to the wide range of anthropogenic environmental impacts, a number of types of environmental audits have been formed in domestic and international practice, each of which is focused on achieving various specific goals. Let's consider some of them:

1) Compliance audit, which is to determine the compliance of economic activity with environmental legislation;

2) Audit of management, which consists in assessing the effectiveness of the management system, compliance with the established internal management system and corporate policy, determining the degree of environmental risk associated with the activities of the enterprise;

3) The audit of supply, which consists in assessing the environmental safety of raw materials, materials, equipment used in the products' manufacturing, identifying alternative resource-saving technologies that help to reduce the cost of goods produced;

4) An audit of real estate, including an assessment of past economic damage from pollution, as well as potential environmental liability in the implementation of the privatization value of an enterprise or land plots with real estate objects located on them;

5) The audit of waste treatment includes an assessment of the hazard of production wastes by their recovery, recycling, location and disposal;

6) The audit of the territories is associated with the assessment of the rational use of territories for various objects in order to create an optimal environmental situation;

7) The energy saving audit includes an assessment of energy consumption and the identification of possible ways to reduce it;

8) Strategic audit is associated with the assessment of a prospective business strategy, taking into account the environmental characteristics of the enterprise and identifying potential business partners with an environmentally oriented management system;

9) Insurance environmental audit is associated with risk assessment and determination of the extent of damage in case of man-made accidents, technological failures, natural processes for the justification and implementation of environmental insurance;

10) The audit of accumulated damages consists in assessing the environmental hazard for past accumulated damages in an enterprise or a facility when switching to another type of property;

Investment environmental audit is associated with the assessment of the necessary expenses for the environmental aspects of the activity when investing to expand, reconstruct, restructure, or close the enterprise.

One of the main requirements for an environmental audit is the simplicity and accessibility of the procedure for its conduction in management and execution.

Before conducting an environmental audit, it is necessary to prepare the company for the procedure according to the following scheme:

1. To identify the processes that are used in the commercial activities of the enterprise or in the production process of the object of audit;

2. To determine the target orientation of the policies and plans of the enterprise;

3. To determine the competence of the audit, including its structure and scale;

To develop procedures that establish an audit procedure.

By its nature, an environmental audit may be internal or external. 
Internal audit involves the implementation of the audit by employees of the company, which are instructed by management the formation of the "audit team". External performers may also be involved.

External audit is the signing of an audit contract by a specialized audit firm or specialists licensed for this type of activity and forming an "audit team", which may also include representatives of the enterprise. Regardless of whether the company employees conduct an environmental audit or external specialists, the main requirements for specialists who will conduct an environmental audit are: qualification, impartiality and objectivity. It should also be noted that a rather difficult task is to ensure the effective functioning of the environmental management system; accordingly, environmental auditing should be carried out to identify those areas and aspects of activity that are not yet sufficiently formed and developed.

An environmental audit should be beneficial to the management of the enterprise, since its results allow determining whether the environmental management and management system works as it should work in accordance with the stated environmental policy and objectives $[9,10]$.

Ecological audit of an industrial enterprise can be carried out in such areas as: production environmental audit, environmental audit of financial activities and environmental audit for compliance (Fig. 1).

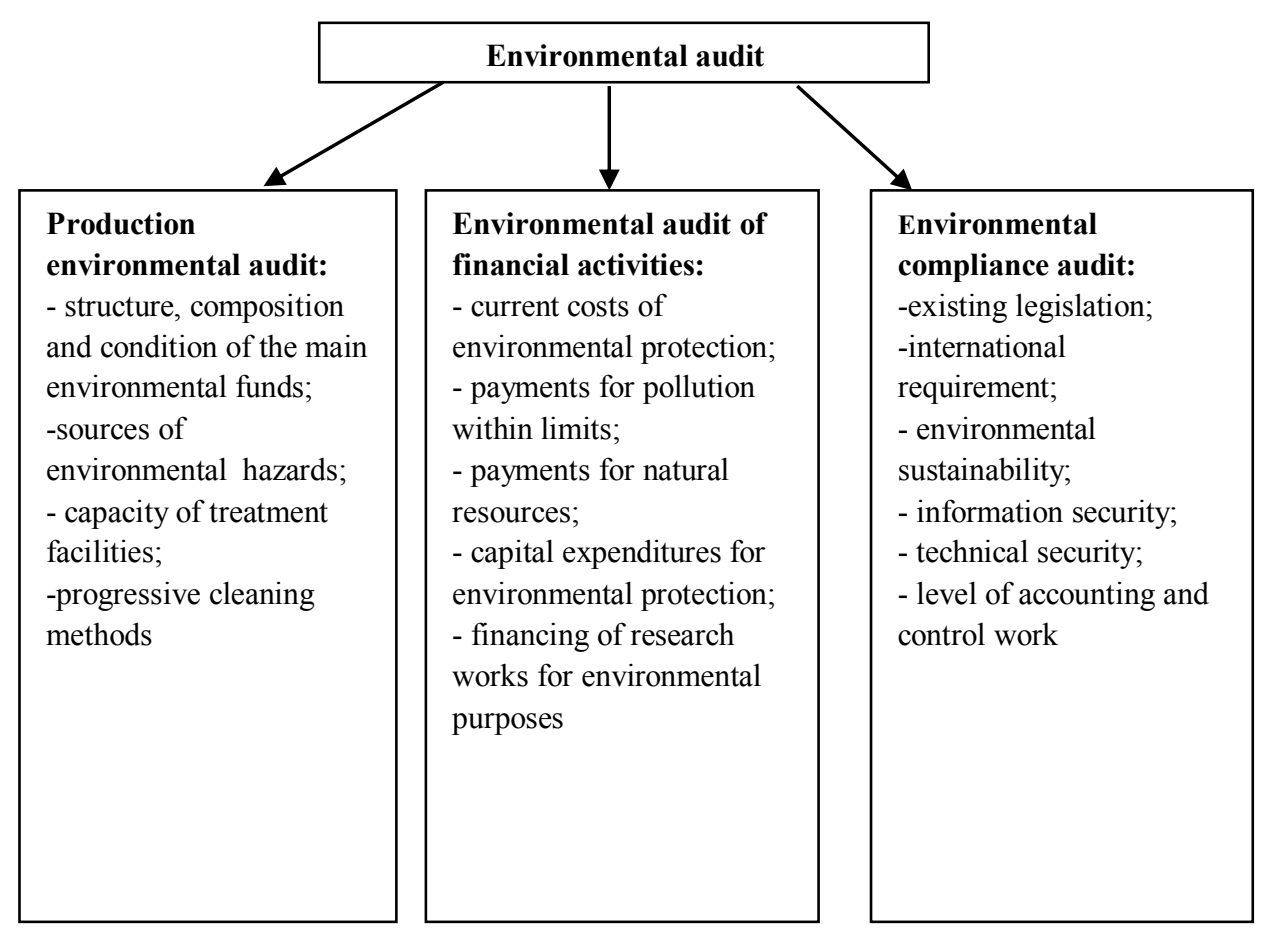

Fig. 1. The structure of the environmental audit of industrial enterprises

In accordance with Figure 1, it can be noted that the environmental audit addresses issues related to the assessment of the rational use of the resources available to the enterprise and the determination of the possible magnitude of various emissions to the atmosphere, lithosphere and hydrosphere. 
However, the scope of the environmental audit is not limited to this. The most important direction of the development of the environmental audit system is the improvement of the mechanism of interconnections between its various areas: industrial environmental audit, environmental audit of financial activities and environmental audit for compliance.

One of the interesting models that allow a comprehensive assessment of the interconnection between the financial and environmental indicators is the model proposed by the authors from the St. Petersburg State Technical University n.a. Peter the Great [11].

This work presents a modernized system of balanced indicators, taking into account the relationship between various financial and non-financial indicators, which allows developing an approach to sustainable environmental development (using the example of the Murmansk region).

Another important direction of environmental audit, which will be discussed in this paper, is the analysis of economic losses associated with the level of injuries in a manufacturing enterprise. Timely identification and assessment of such losses can serve as a guide for industrial enterprises to prevent injuries and formulate a budget for activities related to the treatment of industrial injuries.

Development of measures aimed at reducing production risk and the number of industrial injuries is carried out in the form of an innovation and investment project, for the evaluation of which effectiveness it is not enough to use only traditional methods for evaluating investment projects [12].

As the main result of an innovative project aimed at increasing the safety of production facilities during their operation, the economic effect associated with a decrease in the number of accidents (industrial injuries) is considered. The main sources of such injuries are: technical failure of joints, assemblies and production equipment systems.

As an integral criterion of the socio-economic efficiency of such an innovative project, the authors propose to consider the magnitude of the reduction of economic damage from industrial injuries (Economic loss, EL), which can be defined as the multiplication of the probable decrease in the number of occupational injuries during the implementation of an innovative project and the average value of the magnitude of the damage and is calculated using the following formula:

$$
E L=R N I * A V M D,
$$

where reducing the number of injuries (RNI) - probable decrease in the number of occupational injuries during the implementation of an innovative project, the average value of the magnitude of the damage (AVMD) - average value of the magnitude of the damage. Thus, the basis for evaluating the effectiveness of targeted programs and activities aimed at reducing injuries of employees of industrial enterprises in the course of their professional activities is the method of expressing in monetary terms the economic benefits that society will receive due to the prevention of industrial accidents.

The magnitude of the socio-economic effect of innovation will be determined by us based on the economic assessment of damage from industrial accidents.

When analyzing the domestic methodology for recording losses of the country's economics from the accidents arising at work, the authors found that it requires adjustment in accordance with changes in economic relations [13].

As suggestions for improving the methodology, we offer the following:

1) Provide a cost estimate of the damage AVMD, which falls on one case of work injury, in the form of the following costs:

- economic losses due to the retirement of a person from the sphere of production, $\mathrm{C}_{\mathrm{r}}$;

- cost of medical care, $\mathrm{C}_{\mathrm{mc}}$;

- cost of actions performed by administrative and rescue services, Cars; 
- valuation of loss of «well-being», $\mathrm{C}_{\text {lwb }}$;

- valuation of damage to someone's property, $\mathrm{C}_{\mathrm{vdsp}}$.

$$
A M V D=C_{r}+C_{m c}+C_{c a r s}+C_{l w b}+C_{v d s p}
$$

Let's consider methods of calculation of all components of damage.

The valuation of damage caused by damage to a particular person, as well as the loss of "well-being", is further divided into the following three groups of victims:

- dead $\mathrm{C}_{\text {lwbd; }}$;

- severe injured $\mathrm{C}_{\text {lwbsi }}$;

- slightly injured $\mathrm{C}_{\mathrm{lwbli}}$.

$$
C_{l w b}=C_{l w b d}+C_{l w b s i}+C_{l w b l i}
$$

The division into three groups is due to the serious difference in the economic security for reducing the severity of the consequences of accidents at work.

Socio-economic damage from one reported case of industrial injurie with victims is calculated as the sum of all components of damage divided by the number of cases of industrial injurie with victims, which were taken into account by official statistics. This meter is used in connection with its certainty and accuracy. The data for all reported cases of industrial injuries are more uncertain due to the frequent concealment of information on some part of the cases of industrial injuries.

The official statistics published in the Russian Federation does not contain detailed data on cases of industrial injuries (no division of victims of industrial accidents by categories is made, depending on whether the injury was "severe" or "light").

Particular indicators taken into account for the purpose of estimating losses: $\mathrm{C}_{\mathrm{r}}$.

a) Valuation of losses due to the retirement of a person from the sphere of production

Economic losses due to the retirement of a person from the production sphere are estimated as incomes that will not be received as a result of death, disability or temporary absence of a person in the labor market. These losses were calculated separately for the dead, people who suffered severe injuries, and people who received minor injuries. In general, the damage resulting from the industrial injuries, due to the retirement of a person from the sphere of production, is determined by the formula:

$$
C_{r}=C_{r d} * N_{d}+C_{r s i} * N_{s i}+C_{r l i} * N_{l i}
$$

where $\mathrm{C}_{\mathrm{rd}}, \mathrm{C}_{\mathrm{rsi}}, \mathrm{C}_{\mathrm{rli}}$ - damage due to retirement of a person from the sphere of production, respectively, for one dead, seriously injured and lightly injured, rub.;

$\mathrm{N}_{\mathrm{d}}, \mathrm{N}_{\mathrm{si}}, \mathrm{N}_{\mathrm{li}}$ - the number of respectively dead, seriously injured, lightly injured as a result of industrial injuries.

b) Cost of medical care Cmc.

The costs of medical care should cover all the direct costs of health facilities associated with industrial injuries, for example, hospitalization and hospital treatment, outpatient treatment, etc.

The costs attributable to the three groups of industrial injuries (allocated depending on the severity of the consequences), it is proposed to calculate on the basis of the following data:

- information about the length of stay in hospital $\left(\mathrm{T}_{\mathrm{si}}=150\right.$ days for severe injuries and $\mathrm{T}_{\mathrm{li}}=30$ days for lightly injured workers); 
- expert estimates of unit costs for hospitalization $\left(C_{h}=1000 R U B /\right.$ bed-day in prices of 2017).

Thus, in the general case, the cost of providing medical care from one case of industrial injury is calculated by the formula:

$$
\begin{aligned}
& C_{r}=C_{m d} * N_{d}+C_{m s i} * N_{s i}+C_{m l i} * N_{l i}= \\
& =C_{m d} * N_{d}+T_{s i} * C_{h} * N_{s i}+T_{l i} * C_{h} * N_{l i},
\end{aligned}
$$

where $\mathrm{C}_{\mathrm{md}}, \mathrm{C}_{\mathrm{msi}}, \mathrm{C}_{\mathrm{mli}}$ - medical costs respectively for one dead, seriously injured and lightly injured worker, rub.;

c) Valuation of actions performed by the administrative authorities and the rescue service, $\mathrm{C}_{\text {cars. }}$.

The costs of services by the administrative authorities and the rescue service should cover the costs of putting in order the place where there an industrial injurie happened, and informing the relevant services about the industrial injurie case that occurred, broken down depending on the degree of consequences.

d) Indicator of the valuation of the loss of "well-being" of a person $\mathrm{C}_{1 \mathrm{wb}}$.

To determine this indicator, the authors propose to use the Danish method of assessing the loss of "well-being", or deprivation of properties that constitute the value of the human being $[14,15]$. Its implementation is carried out by multiplying on the corresponding coefficient the valuation of the damage caused by the harm implemented to a specific person (economic losses due to the disposal of a person from the sphere of production, the cost of medical care and actions performed by the administrative authorities and the rescue service).

In this method, the following values of the factors mentioned above are determined:

-2 for the dead;

- 1/3 for persons injured severely;

- 1/15 for persons with minor injuries.

Thus, the damage from the industrial injury as a result of the loss of a person's "well-being" $\mathrm{C}_{\text {lwb }}$ can be determined by the formula:

$$
\begin{aligned}
& C_{l w b}=2 \cdot\left(C_{l w b d}+C_{m d}+C_{a s d}\right) * N_{d}+\left(\frac{C_{l w b s i}+C_{m s i}+C_{a s s i}}{3}\right) * N_{s i}+ \\
& +\left(\frac{C_{l w b l i}+C_{m l i}+C_{a s l i}}{15}\right) * N_{l i},
\end{aligned}
$$

where $\mathrm{C}_{\text {asd }}, \mathrm{C}_{\text {assi }}, \mathrm{C}_{\text {asli }}$ - the costs of actions performed by the administrative and the rescue services, respectively, per one dead, severe injured and slightly injured, rub.

In our opinion, this component of damage should additionally take into account the previously unaccounted costs of loss of working time by family members of the victim or the victim of the industrial injury, as well as expenses due to the difficulty of the enterprise due to the temporary absence of the employee at work due to injury.

The proposed particular indicators a) -d) make up the cost estimate of the total damage caused by the damage to health caused to a specific employee who was injured.

On their basis, a calculation was made of the total damage per person suffered of industrial injuries at industrial enterprises of the Nizhny Novgorod region (according to 2017 data).

The results of calculations relating to the three categories of persons affected by industrial injuries are presented in Table 1. 
Table 1. Cost estimate of the total damage caused by damage to a particular employee, including the loss of "well-being", per one victim from industrial injuries, 2017.

\begin{tabular}{|c|c|c|c|c|}
\hline № & $\begin{array}{c}\text { Components of the damage caused } \\
\text { by industrial injuries in industrial } \\
\text { plants }\end{array}$ & $\begin{array}{l}\text { For one } \\
\text { dead }\end{array}$ & $\begin{array}{l}\text { Per one person } \\
\text { who with severe } \\
\text { injuries }\end{array}$ & $\begin{array}{l}\text { Per one person } \\
\text { with light } \\
\text { injuries }\end{array}$ \\
\hline 11 & $\begin{array}{l}\text { The shortfall in the results of } \\
\text { production activities, ths. rub. }\end{array}$ & 673.4 & 124.4 & 4.62 \\
\hline 22 & The cost of medical care, ths. rub. & 3 & 150 & 30 \\
\hline 33 & $\begin{array}{l}\text { The cost of the services of } \\
\text { administrative authorities and the } \\
\text { rescue service, ths. rub. }\end{array}$ & 1.5 & 1.8 & 2.5 \\
\hline 44 & $\begin{array}{l}\text { Damage caused by the death and } \\
\text { injury of an employee, ths. rub. }\end{array}$ & 677.9 & 276.2 & 37.12 \\
\hline 55 & Coefficient of loss of "well-being" & 2 & $1 / 3$ & $1 / 15$ \\
\hline 66 & $\begin{array}{l}\text { Damage as a result of the loss of } \\
\text { "well-being", ths. rub. }\end{array}$ & 1355.8 & 92.07 & 2.47 \\
\hline 77 & $\begin{array}{l}\text { Total damage resulting from the } \\
\text { death and injury of workers, } \\
\text { including the loss of "well-being", } \\
\text { ths. rub. }\end{array}$ & 2033.7 & 368.27 & 39.59 \\
\hline
\end{tabular}

e) The valuation of damage to property $\mathrm{C}_{\mathrm{vdsp}}$.

The valuation of damage to property should cover society's costs associated with general property damage. This means that damage to property includes damage resulting from damage to the means of production, clothing of injured workers, and in addition, previously ignored material damage from damage to other types of property should be taken into account.

In our opinion, the proposed calculations should be carried out annually. The result will be annual property damage from industrial injuries in Russia. Today, according to experts, it is about $1 \%$ of the country's GDP, which is more than 100 billion rubles.

\section{Results and discussion}

Taking into account the data obtained, the main indicator of the socio-economic effect according to the data of 2017 is determined by the formula:

$$
E L=835711 * R N I, \quad r u b .
$$

In addition, we would like to note that in a market economics, the norm of damage from the death or injury of an employee cannot be calculated and set in absolute terms, which can be used for a long period. This is due to the fact that the damage assessment depends on the value of GDP, as the main indicator of a country's economic potential.

Thus, the proposed method for assessing the socio-economic efficiency of innovative projects to the industrial safety management system of enterprises is based on taking into account industry specifics (determining the damage components of cases of industrial injuries). Its practical application will make it possible to envisage for enterprises working with priority innovations for the state, subsidies or other incentive mechanisms, taking into account their public importance.

\section{Conclusion}


As part of this work, the authors considered an environmental audit system as a tool to improve the safety of an industrial enterprise, analyzed the evolution of this direction as a theoretical and practical area, considered improving the regulatory and legal component of this process, the structure of environmental auditing at an industrial enterprise.

As part of the practical part of the study, the authors proposed an approach to evaluating an innovative project aimed at reducing industrial injuries among industrial workers, which is an improvement to existing methods for evaluating innovative investment projects and projects related to occupational safety. The socio-economic efficiency of the project was assessed on the example of industrial enterprises of the Nizhny Novgorod region, indicating its feasibility and applicability as an appraisal methodology and justifying actions to improve the system of measures aimed at improving occupational safety.

\section{Result}

The result of this work is the definition of socio-economic efficiency of the innovative project, based on the principles of environmental audit aimed at reducing industrial injuries in industrial enterprises.

The study was carried out with the financial support of RFBR within the scientific project № 19-01000932 (head of the grant -Yashin S. N., 2019.)

\section{References}

1. The audit is in 2 parts. Part 1: tutorial and workshop for undergraduate and graduate/ under the editorship of M. A. Stefan (2019)

2. https://www.iso.org/iso-14001-environmental-management.html (Last accessed 13.04.2019)

3. http://docs.cntd.ru/document/1200134681(Last accessed 03.05.2019)

4. T. Trifonova, Environmental management: textbook (2009)

5. M. Brinchuk, Environmental law: textbook (2009)

6. http://www.consultant.ru/document/cons doc LAW 83311/ (Last accessed 12.05.2019)

7. T. Sergeeva, Environmental audit. Textbook for University students (2009)

8. http://ecolog-region.ru (Last accessed 22.04.2019)

9. S. Ljubisavljević, L.Ljubisavljević, D. Jovanović. Economic Themes, 55(4) (2017)

10. W. Cook, S. Bommel, Esther Turnhout. CurrentOpinioninEnvironmental Sustainability, 18, 33-39 (2016)

11. A. Kozlov, S. Gutman, I. Zaychenko, E. Rytova, P. Nijinskaya, Environmental management on the basis of Complex Regional Indicators Concept: case of the Murmansk region, IOP Conference Series: Materials Science and Engineering 6. (2015)

12. S. Yashin, D. Sukhanov, Health and safety, 3, 67- 69 (2017)

13. http://eisot.rosmintrud.ru/attachments/article/309/mopz.pdf (Last accessed 08.05.2019)

14. O. Prituzhalova, Environmental management and audit: textbook. Manual for universities (2019)

15. https://www.irsst.qc.ca/media/documents/PubIRSST/R-787.pdf (Last accessed 23.04.2019) 
